\title{
A Comparison of Sodium Silicate and Ammonium Lignosulfonate Effects on Xenotime and Selected Gangue Mineral Microflotation
}

\author{
Yicheng Zhang and Corby Anderson \\ Kroll Institute for Extractive Metallurgy, Colorado School of Mines, \\ 1500 Illinois Street, Golden, CO, 80401
}

\begin{abstract}
Because of their selective depressing power, sodium silicate and lignosulfonate have been widely used as depressants in rare-earth mineral flotation to separate minerals from specific types of gangue minerals. In this project, the microflotation of a xenotime pre-concentrate and pure samples of the selected gangue minerals ilmenite, zircon, schorl and staurolite was carried out. This utilized octano-hydroxamic acid and sodium oleate as the collectors and the research was conducted in a Partridge-Smith microflotation cell. The flotation of the mixed samples (weight ratio=1:1) of xenotime and each one of its gangue minerals was also investigated at both room temperature and $80^{\circ} \mathrm{C}$, using sodium silicate or ammonium lignosulfonate in the presence of octano-hydroxamic acid and sodium oleate respectively. The flotation results are described and compared with those observed by previous researchers. The effects of sodium silicate and ammonium lignosulfonate on weight recoveries and grade of xenotime are also discussed and compared.
\end{abstract}

Key words: Xenotime, Microflotation, Sodium silicate, Ammonium lignosulfonate.

\section{Introduction}

Sodium silicate, widely used as a depressant in rare earth mineral flotation to separate minimally soluble minerals from siliceous gangue minerals[1], has been studied through the last five decades.

In 1965, using sodium silicate as depressant in the presence of sodium oleate, Viswanathan et al. selectively separated monazite from its associated gangue minerals[2]. In 1981, Pradip stated that work by Illie in 1966 also enhanced the recovery of monazite from $77 \%$ to $90 \%$ by using both sodium silicate and $\mathrm{Na}_{2} \mathrm{~S}$ as depressants[3]. In 1990, Dho and Iwasaki concluded that the effect of sodium silicate was attributed the higher specific flotation rate of phosphate over silicate minerals, thus enhancing the selectivity of separation[4]. In 2010, Silva et al investigated the use of sodium silicate with the use of FTIR spectra. It was found that the depressing power of sodium silicate increased correspondingly with its concentration. Almost a complete depression of calcite and quartz was achieved with concentrations above $1500 \mathrm{~g} / \mathrm{l}[5]$. The most successful use of sodium silicate as a depressant is in its application in the mine. There it is used to depress silicates before the Bayan Obo addition of a naphthyl hydroxamic acid collector. At the low alkaline conditions used, the depressing power of sodium silicate helps to upgrade the rare earth minerals concentrate from $9.78-12 \%$ to 34-55\% TREO content[6].

Lignosulfonate, a byproduct from the production of paper using sulfite pulping, is also well known as a depressant in the flotation of rare earth minerals.

In 1968, Helmut et al. found that lignosulfonate possessed the power to depress silica in froth flotation[7]. In 1975, Browning indicated that the adsorption of lignosulfonate on a mineral surface happened by chemical hydrogen bonding[8]. Further, in 1981, Pradip found that temperature had little effect on the performance of lignosulfonate as a depressant[3]. In contrast, Anderson in 2015 concluded the opposite in that a sharp increase in recovery and grade occurred by increasing the 
temperature of a flotation operation from $25^{\circ} \mathrm{C}$ to $80^{\circ} \mathrm{C}[9]$.

More importantly, is utilization of the depressing power of lignosulfonate on iron-bearing gangue minerals. In 1986 Weir et al successfully recovered gold from refractory auriferous iron-containing sulphidic concentrates by using lignosulfonate as a depressant[10]. In 2008 Sun and Yi significantly upgraded limonite by reverse flotation by using lignosulfonate as the depressant[11]. The commercial application of lignosulfonate as a depressant also appears in the industrial flotation of bastnaesite ore at Mountain Pass in California. There ammonium lignosulfonate is added in a steam heated conditioning stage before the addition of steam-distilled tall oil C-30, in order to depress barite[12].

While sodium silicate and lignosulfonate have been widely investigated and used in rare-earth mineral flotation, their application in the flotation of xenotime has apparently been minimal, when compared to that of bastnaesite and monazite. So, in order to better understand the effect of sodium silicate and ammonium lignosulfonate on xenotime flotation, in this research, a pre-concentrated xenotime sample and four common gangue minerals (ilmenite, zircon, schorl and staurolite) were used in lab-scale microflotaion tests. These were conducted in a Partridge-Smith microflotation cell. Comparisons were made between the performance of sodium silicate and ammonium lignosulfonate as the depressants in experiments conducted under differing conditions.. This was also studied in the presence of octano-hydroxamic acid and sodium oleate collectors.

\section{Materials and Methods}

The pre-concentrated xenotime sample used in this project was obtained from a Chinese rutile mining plant in Hainan Province, China. Xenotime is a byproduct of beach placer deposits and it had been separated and concentrated from rutile ores by washing, Wilfley table concentration, electrostatic separation and finally magnetic separation. As shown in Table 1, Mineral Liberation Analyzer (MLA) analysis on this concentrate indicated that xenotime $\left(\mathrm{YPO}_{4}\right)$ was the major phase present at $67.7 \%$ by weight. An iron-titanium oxide phase called pseudo-rutile was found to be $12 \%$, followed in abundance by silicates-staurolite $6 \%$, zircon $4 \%$, and schorl 3\%. Since pseudo-rutile is a weathering product of ilmenite, and a FeTiO-bearing mineral similar to ilmenite, ilmenite was chosen as one of the four major gangue minerals. The other three minerals utilized were zircon, schorl and staurolite. The proposed formulas for these are shown in Table 1. All four gangue minerals were obtained as crystals. All of the xenotime concentrate and the gangue minerals were pulverized in an Angstrom TE250 Ring Pulverizer to a $200 \times 400$ US mesh size fraction. These materials were then washed and dried for experimental use.

Table 1: MLA Mineral Content of the Xenotime Concentrate

\begin{tabular}{l|l|c}
\hline Mineral & Formula & Modal $(w t \%)$ \\
\hline Xenotime & $\mathrm{YPO}_{4}$ & 67.7 \\
\hline $\begin{array}{l}\text { Pseudorutil } \\
\text { e }\end{array}$ & $\mathrm{Fe}_{2} \mathrm{Ti}_{3} \mathrm{O}_{9}$ & 11.6 \\
\hline Staurolite & $\mathrm{Fe}_{2} \mathrm{Al}_{9} \mathrm{Si}_{4} \mathrm{O}_{20}(\mathrm{OH})_{4}$ & 5.94 \\
\hline Zircon & $\mathrm{ZrSiO}_{4}$ & 4.00 \\
\hline Schorl & $\mathrm{NaFe}_{3} \mathrm{Al}_{6}\left(\mathrm{BO}_{3}\right)_{3} \mathrm{Si}_{6} \mathrm{O}_{18}(\mathrm{OH})_{4}$ & 3.05 \\
\hline Others & $/$ & 7.71 \\
\hline
\end{tabular}

The two collectors used, sodium oleate $\left(\mathrm{C}_{18} \mathrm{H}_{33} \mathrm{NaO}_{2}\right)$ and Octano-hydroxamic $\operatorname{acid}\left(\mathrm{C}_{8} \mathrm{H}_{17} \mathrm{NO}_{2}\right)$ were both supplied by Tokyo Chemicals Inc. One depressant used, pentahydrate sodium silicate $\left(\mathrm{Na}_{2} \mathrm{SiO}_{3} \cdot 5 \mathrm{H}_{2} \mathrm{O}\right)$ was obtained from unknown supplier; the other depressant used, ammonium lignosulfonate $\left(\mathrm{C}_{20} \mathrm{H}_{26} \mathrm{O}_{10} \mathrm{~S}_{2}\right.$ for lignin sulfonate) was supplied by HBC Chem Inc.

In this research, zeta potential measurement was conducted with the Stabino, produced by Microtrac. Before performing Stabino testing, the equilibrium time of samples in solution was determined first through adsorption tests. Then the samples for Stabino tests were prepared for a longer time. In this case, the samples for zeta potential measurements were first ground in a pulverizer to $200 \times 400$ mesh. Then $0.02 \mathrm{~g}$ of each mineral was added in $40 \mathrm{~mL}$ distilled water. The $\mathrm{pH}$ was adjusted as required with $\mathrm{NaOH}$ and $\mathrm{HCl}$.

In the research more than 300 microflotation tests were conducted using a Partridge-Smith microflotation cell. Replicate tests were conducted on each benchmarking test and the reproducibility was excellent. In each benchmarking test, $0.5 \mathrm{~g}$ of mineral sample (or a mixed sample of xenotime and the gangue minerals) was stirred with $40 \mathrm{ml}$ of collector solution with the concentration ranging 
from $0.0005 \mathrm{M}$ to $0.002 \mathrm{M}$, in a $100 \mathrm{ml}$ beaker for 15 minutes at set $\mathrm{pH}$ values. After conditioning, the sample was transferred to the microflotation cell. 10 $\mathrm{ml}$ of the collector with the correct concentration and $\mathrm{pH}$ was added and also used to wash down any residual material in the beaker to the cell.

In each test with depressant addition, $0.5 \mathrm{~g}$ of sample was conditioned with $25 \mathrm{ml}$ of $0.001 \mathrm{M}$ depressant first for 5 minutes and then for 15 minutes after the addition of $15 \mathrm{ml}$ of collector solution with concentrations ranging from $0.001 \mathrm{M}$ to $0.004 \mathrm{M}$. After conditioning, the sample was transferred to the cell and $10 \mathrm{ml}$ of the collector with the correct concentration and $\mathrm{pH}$ was used to wash down any residual material in the beaker to the cell.

The $\mathrm{pH}$ in the tests was modified with either $\mathrm{NaOH}$ or $\mathrm{HCl}$. The $\mathrm{pH}$ was measured before conditioning with a $\mathrm{pH}$ meter. Elevated temperature tests were performed by heating the samples to $80^{\circ} \mathrm{C}$ during conditioning.

After the pulp was transferred, it was stirred with a magnetic bar in the cell at $600 \mathrm{rpm}$. The compressed air flow addition rate was maintained at $30 \mathrm{cc}$ per minute. After 2 minutes of flotation, the concentrate and tailings were filtered and dried for weighing. Then the dried concentrate was prepared for XRF analysis, in order to determine the content.

Using different reagents, the experimental variables evaluated in the microflotation tests included $\mathrm{pH}$, temperature and reagent concentration. Other variables like gas flow rate and particle size were not tested in this project.

The error bars presented represent the standard deviation of the experimental data gained from the benchmarking tests. The magnitude of experimental error was within the allowable range, having no effect on qualitative analysis.

\section{Results and Discussion}

In benchmarking tests, no depressants were used. Octano-hydroxamic acid (HXM) and sodium oleate (SOT) collectors were tested with varying conditions. Figure 1 shows that the weight recovery of xenotime increased when the concentration of HXM was increased from $0.0001 \mathrm{M}$ to $0.0005 \mathrm{M}$. The weight recovery was constant above $96 \%$ even when the concentration of HXM was increased to $0.002 \mathrm{M}$. This likely indicates that the concentration of HXM has already reached its adsorption equilibrium at $0.0005 \mathrm{M}$.

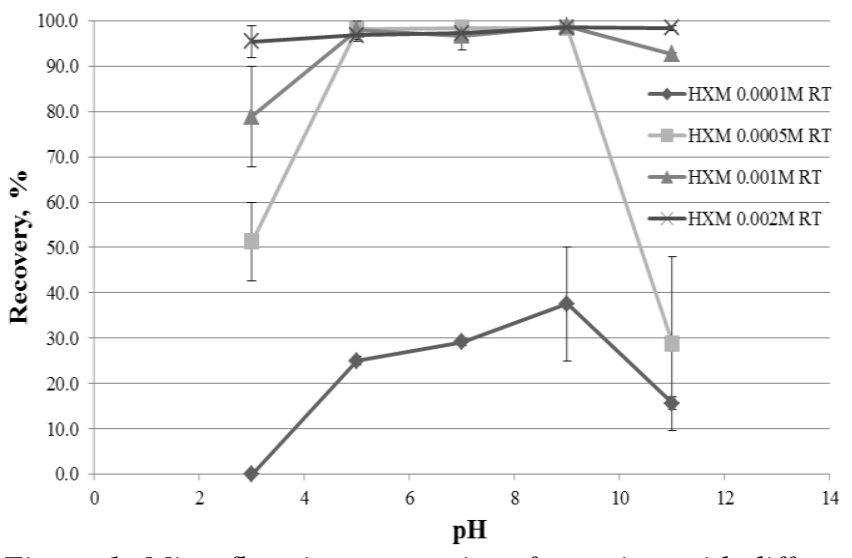

Figure 1: Microflotation recoveries of xenotime with different concentrations of octano-hydroxamic acid as a function of $\mathrm{pH}$ at room temperature

A plateau of maximum weight recovery was observed in the range of $\mathrm{pH} 5$ to 9. Sharp drops in weight recovery were observed when the $\mathrm{pH}$ was lower than 5 or greater than 9 and when the concentration of HXM was relatively low. Similar observations were also made by Pradip in 1981 when using K-octyl hydroxamate as the collector in bastnaesite flotation[3] and also by Quast in 2000 when using K-dodecyl hydroxamate as the collector in hematite flotation[13].

Pradip [3] and Anderson [9] have confirmed that hydroxamic acid is chemisorbed onto metallic minerals, including xenotime. In this project, it is also suggested that the mechanism of adsorption using this collector was chemisorption. This is based upon the thermodynamic calculation and comparison of the free energies of adsorption for octano-hydroxamic acid on the surface of the minerals at both room temperature and $80^{\circ} \mathrm{C}$ (Figure 2).

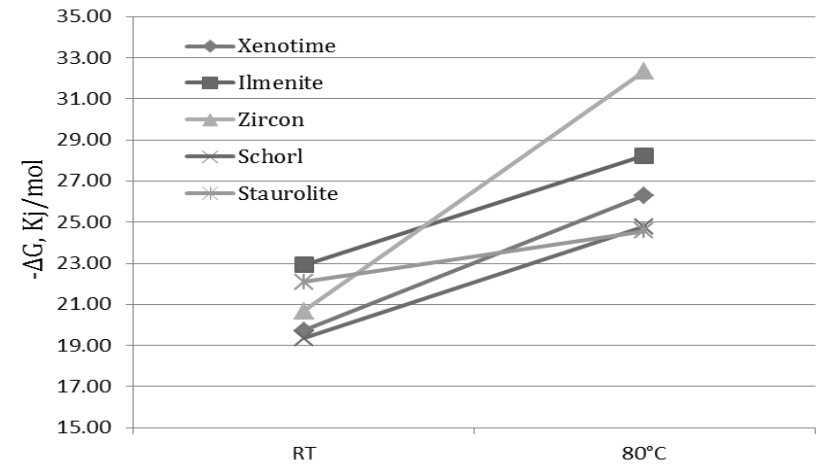

Figure 2: Comparison of Free Energies of Adsorption of Octano-hydroxamic Acid at Room Temperature and $80^{\circ} \mathrm{C}$

In addition, as evaluated by Pradip in 1981[3] and Anderson in 2015[9], metal ions $\mathrm{M}^{3+}$ (such as $\left.\mathrm{La}^{3+}, \mathrm{Y}^{3+}, \mathrm{Ce}^{3+}\right)$ are the predominant ions when the 
$\mathrm{pH}$ of solution was lower than 5. $\mathrm{M}(\mathrm{OH})_{3}$ compounds become prevalent when the $\mathrm{pH}$ is higher than 9. This led to the hypothesis that the sharp drop of xenotime recovery at a $\mathrm{pH}$ lower than 5 was because less yttrium ${ }^{3+}$ ions on the xenotime surface can combine with hydroxamic ions. When the $\mathrm{pH}$ is higher than 9, more and more hydroxyl ions compete with hydroxamic ions on the xenotime surface for their adsorption. Both situations lead to the xenotime surface remaining hydrophilic with a lowered recovery. Cheng et al in 1994[14] also made a similar hypothesis. However, in this current research, when the concentration of hydroxamic acid was high enough, the abundance of hydroxamic ions available that could be chemisorbed onto mineral surfaces apparently offset the effect of the $\mathrm{pH}$ values below 5 and above 9. This explains the higher recoveries of xenotime obtained at both $\mathrm{pH} 3$ and 11 when the concentration of HXM is increased from $0.0005 \mathrm{M}$ to $0.002 \mathrm{M}$.

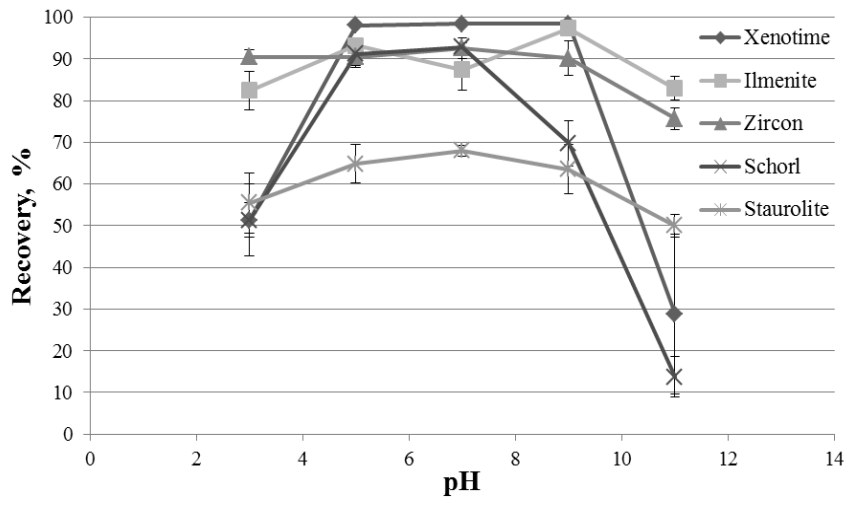

Figure 3: Microflotation recoveries of xenotime and gangue minerals with 0.0005M octano-hydroxamic acid as a function of $\mathrm{pH}$ at room temperature

Similar weight recovery patterns were also observed in the flotation of pure gangue minerals, as show in Figure 3. However, the recoveries of gangue minerals were lower than xenotime in the $\mathrm{pH}$ range of 5 to 9 . This drop in recovery for the ilmenite, zircon and staurolite gangue minerals was not as sharp as that of xenotime. This likely illustrates the selectively of octano-hydroxamic acid when dealing with these minerals. In 2012, Cui et al[15] investigated the selectively of hydroxamate with bastnaesite and potential gangue minerals by using spectroscopic methods. This work also suggested preferential adsorption of hydroxamic ions to rare earth elements.
Further tests were conducted to evaluate the selectivity of octano-hydroxamic acid at $\mathrm{pH}$ 9. The results are shown in Figure 4.

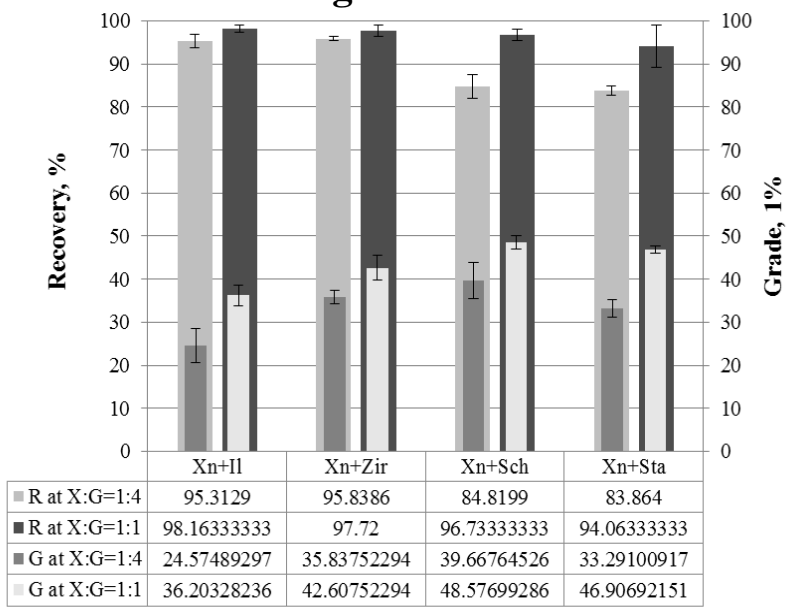

Figure 4: Recoveries and Grade (i.e. Grade of $\mathrm{YPO}_{4}$ ) of mixed samples (weight ratio of xenotime sample and gangue minerals=1:4 and 1:1) with 0.0005M HXM at pH9 at room temperature

Previous literature had concluded, even though maximum recoveries were observed throughout the range of $\mathrm{pH} 5$ to 9 , $\mathrm{pH} 9$ was likely more favorable for hydroxamic acid[3]. The original grade of xenotime, $\mathrm{YPO}_{4}$, in the mixed samples was $13.54 \%$ when the weight ratio was 1:4. It was $33.85 \%$ when the weight ratio 1:1. As shown in Figure 4, the concentrate grade was enhanced each time xenotime was mixed with the gangue minerals. The xenotime recoveries also remained relatively high. In addition, if the initial grade of xenotime in the feed was low, more xenotime was selectively collected. These results lead to the apparent conclusion that octano-hydroxamic acid collector in does exhibit selectivity of xenotime over the gangue minerals.

Comparative flotation tests were also conducted by using sodium oleate collector. As shown in Figure 6, the maximum recovery of xenotime with sodium oleate occurred in the narrower $\mathrm{pH}$ range of 7 to 9. In addition, the gangue minerals had a relatively high recovery in the same $\mathrm{pH}$ range. Similar phenomena were observed by other researchers in the use of sodium oleate as a collector. For example, Cheng et al. in 1993[16] used sodium oleate to float xenotime. Xianfeng in 2009[17] used sodium oleate to float ilmenite. 
Hosten in 2001 used sodium oleate to float zircon[18].

The results of previous surface chemistry studies correlated well with the results of zeta potential determination in this project, as shown in Figure 5. The IEPs determined for these minerals is shown and they all occur below a $\mathrm{pH}$ of 7 .

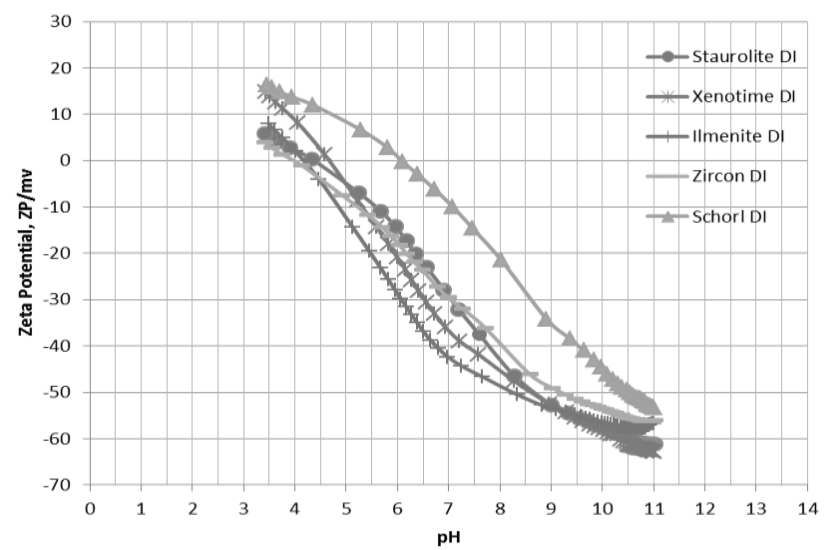

Figure 5 Zeta Potential of Xenotime and Gangue Minerals in Distilled Water

This provides further evidence sodium oleate collector is chemisorbed onto the surface of these minerals. Otherwise poor recoveries would occur in alkaline conditions for anionic collectors like sodium oleate[16]. Pavez et al. in 1995 substantiated this by using FTIR spectrometry to confirm that sodium oleate was chemisorbed onto both bastnaesite and monazite surfaces[19].

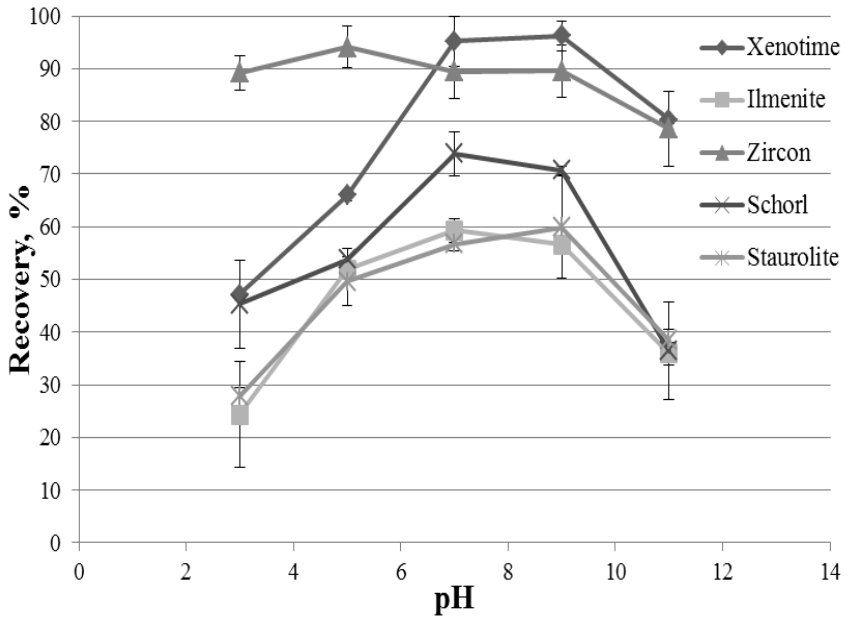

Figure 6: Microflotation recoveries of xenotime and gangue minerals with $0.0005 \mathrm{M}$ sodium oleate as a function of $\mathrm{pH}$ at room temperature.

In this research, the xenotime recovery was found to be lowered when using sodium oleate with $\mathrm{pH}$ lower than 7 and higher than 9. This can likely be explained using the same hypothesis used to explain the sharp drops in recoveries when using hydroxamic acid.

It is interesting to note that the recovery of zircon when either using octano-hydroxamic acid or sodium oleate was not sensitive to $\mathrm{pH}$ changes. Hosten also observed maximum recoveries of zircon over a wider $\mathrm{pH}$ range[18]. This is probably due to the complex surface structure of zircon and its differing interactions with the water phase and the collector molecules.

In this research, a series of experiments was also performed between the effect of octano-hydroxamic acid and sodium oleate collectors on xenotime flotation. This was done as a function of $\mathrm{pH}$ both at room temperature and at $80^{\circ} \mathrm{C}$. As shown in Figures 7(a) and (c), high temperature has a negative influence on the flotation of xenotime when using sodium oleate as the collector at certain $\mathrm{pH}$ values. Conversely, a positive influence is found on the high temperature flotation of xenotime when using octano-hydroxamic acid. Further, lab observations of sodium oleate flotation show that at a $\mathrm{pH}$ lower than 9, bubbles present at high temperature were not stable when compared to those at $\mathrm{pH} 9$ and at $\mathrm{pH} 11$.

It was observed that at a high temperature, small bubbles merged into big ones during floatation and readily broke at the surface of solution. In contrast, the bubble stability when using octano-hydroxamic acid collector remained high even at enhanced temperatures and bubbles appeared to be generated much faster than at room temperature. So, as a result, more xenotime is floated in 2 minutes when using octano-hydroxamic acid at high temperature. The differing effect of temperature on the stability of bubbles when using these two different collectors is still unknown.

Figure 7(b) and (d) suggested that either at room temperature or $80^{\circ} \mathrm{C}$, octano-hydroxamic acid was a powerful collector. This is based on the relative weight recovery of xenotime occurring over a wider $\mathrm{pH}$ range than when using sodium oleate collector. In all cases, regardless of the collector used, more than $95 \%$ of the xenotime sample was recovered at a $\mathrm{pH}$ of 9 . This happened either at room temperature or at $80^{\circ} \mathrm{C}$. Therefore, $\mathrm{pH} 9$ was chosen for all further comparative tests. 


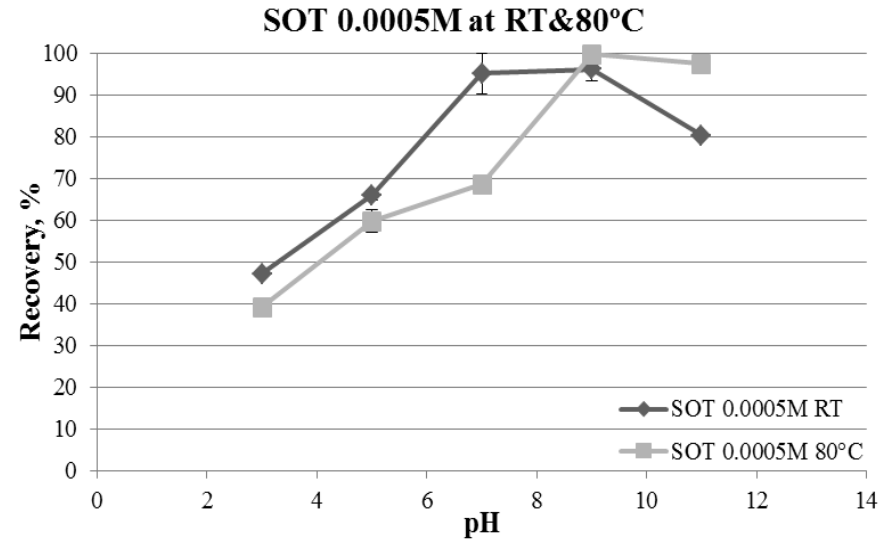

(a)

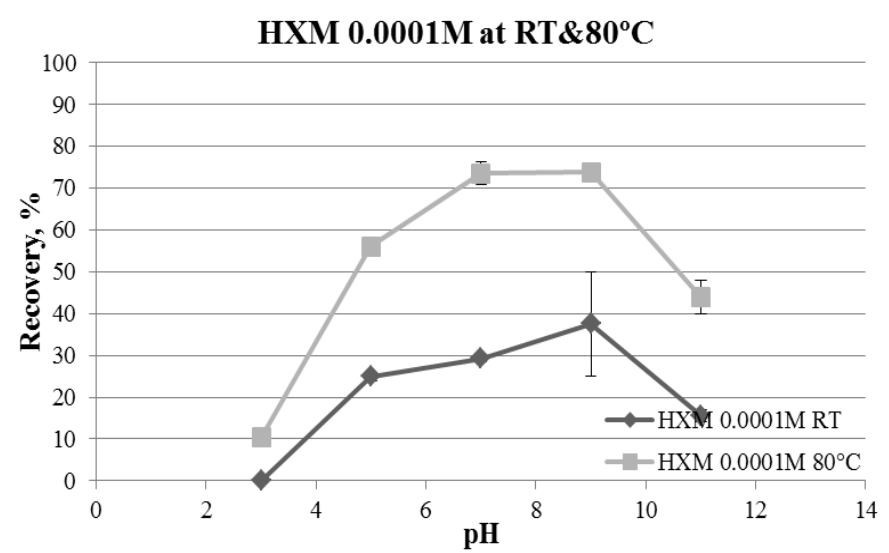

(c)

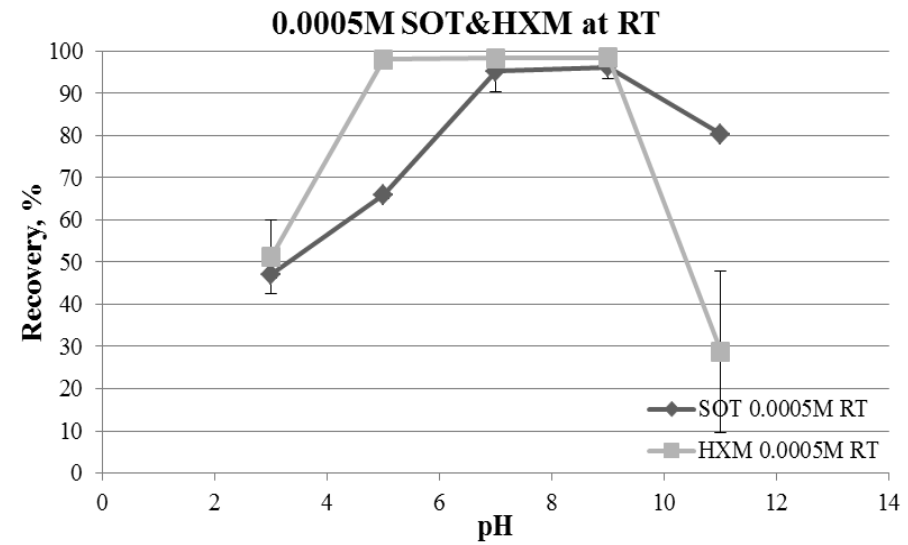

(b)

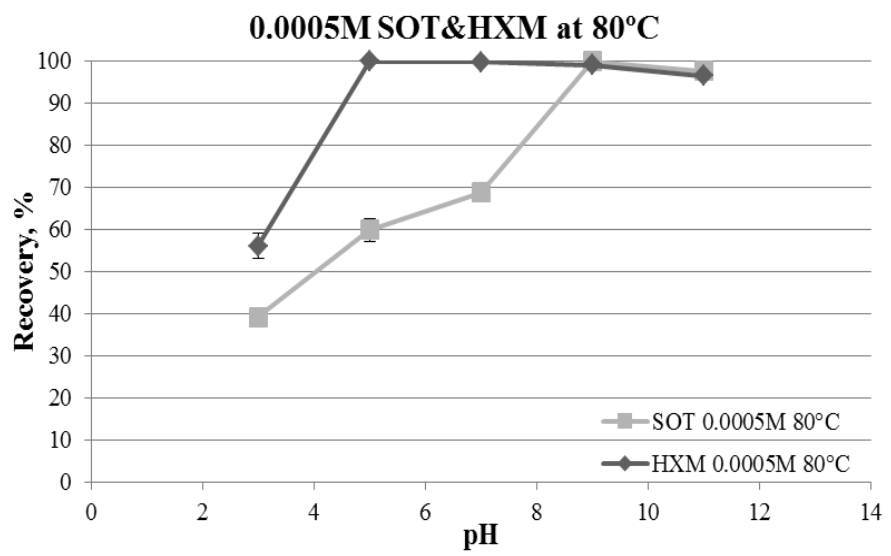

(d)

Figure 7: Comparisons between effects of octano-hydroxamic acid (HXM) and sodium oleate (SOT) on xenotime flotation as a function of $\mathrm{pH}$

First, a comparison of the selectivity between octano- hydroxamic acid and sodium oleate in the absence of depressants was conducted by using mixed samples of xenotime and gangue minerals (weight ratio $=1: 1$ )

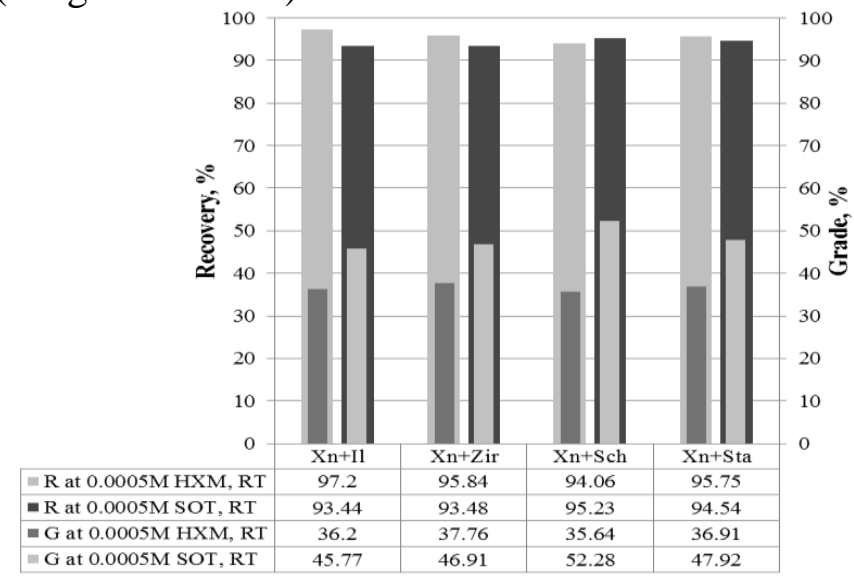

Figure 8: Recoveries and Grades of xenotime with $0.0005 \mathrm{M}$ HXM vs. O.0005M SOT at $\mathrm{pH} 9$ at room temperature

The original grade of xenotime in each mixed sample was $33.85 \%$, and the weight recovery and grade of each concentrate after flotation was measured and calculated. As shown in Figure 8, the recoveries were all above $93 \%$. But the grades obtained by using sodium oleate collector were much higher than those derived by using octano-hydroxamic acid collector. This suggests that at room temperature and at $\mathrm{pH} \mathrm{9,} \mathrm{with} \mathrm{equal}$ collector concentrations of $0.0005 \mathrm{M}$, sodium oleate was more selective than octano-hydroxamic acid in the flotation of xenotime without depressants. Previously Fuerstenau had concluded that hydroxamate was more selective than sodium oleate in the flotation of bastnaesite from barite and calcite [12]. The results of this current research show that sodium oleate is more selective than hydroxamate when floating xenotime from ilmenite and some siliceous minerals. This correlates well with conclusions made by Pavez that hydroxamate seemed to be a weaker activator than sodium oleate in the separation of monazite from zircon[18]. Monazite is another rare-earth-bearing phosphate based mineral like xenotime. The similar phosphate 
based mineralogy may play a key role in this selectivity phenomenon.

In further research conducted, the depressants sodium silicate (SS) and ammonium lignosulfonate (ALS) were used in the flotation of mixed samples. They were added before the addition of octano-hydroxamate acid (HXM) or sodium oleate (SOT) . Analysis was carried out and comparisons were then made based upon the recoveries and grades.

As seen in Figure 9(a), at room temperature and with $\mathrm{pH}$ of 9 , and in the presence of octano-hydroxamic acid collector, the recoveries and grades of xenotime with the use of sodium silicate depressant were slightly better than those obtained with the use of ammonium lignosulfonate depressant. However, both sodium silicate and ammonium lignosulfonate depressants enhanced recoveries and grades. The only exception was when xenotime was mixed with ilmenite. This suggests that both depressants enhance the selectivity of octano-hydroxamic acid collector in the separation of xenotime from the three siliceous gangue minerals. But neither depressant or collector used together had any significant depressing power for ilmenite. No literature has been found that

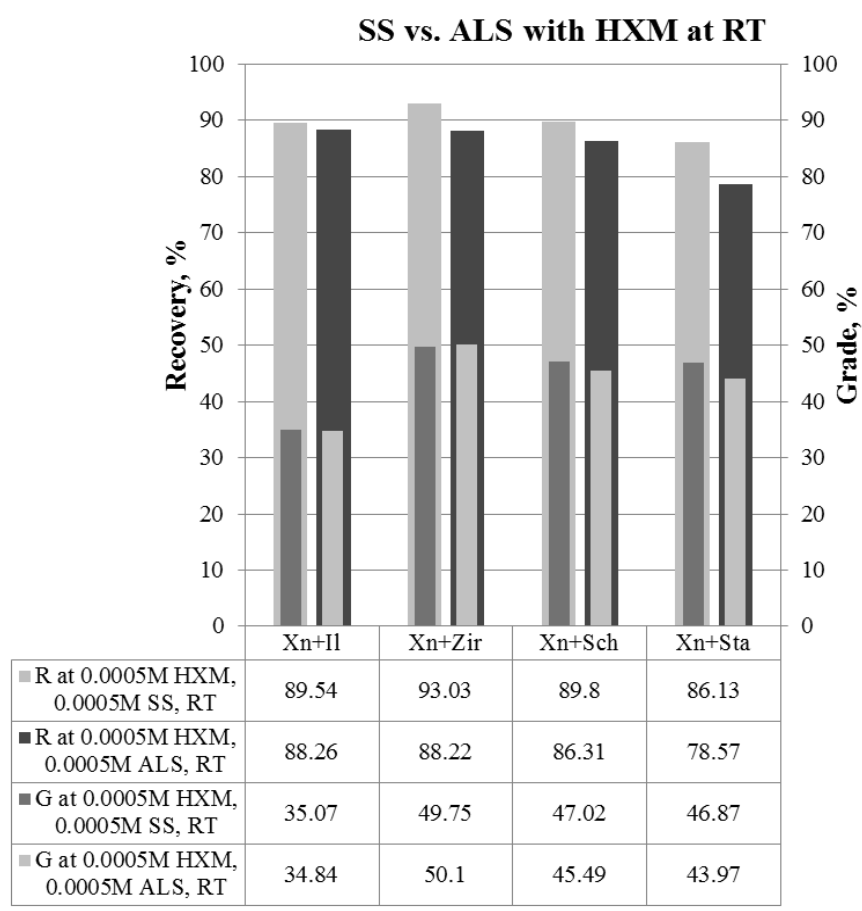

(a) discusses the loss of depressing power of either sodium silicate or lignosulfonate in the separation of xenotime from iron-bearing minerals such as ilmenite. According to a competition theory mentioned previously in this paper, it may be that active $\mathrm{Fe}^{2+}$ ions on the surface of ilmenite favor the octano-hydroxamic collector ion species more than the siliceous ion depressant species or lignosulfonate ion depressant species. Thus no depressing power of ilmenite or was witnessed this research.

The testing of depressants using sodium oleate as the collector resulted in mixed success. As shown in Figure 9(b), at room temperature and a $\mathrm{pH}$ of 9, the recoveries of xenotime in all the mixed samples were lowered by using depressants. This was especially true when using ammonium ligno-sulfonate. In contrast the concentrate grades produced by using sodium oleate collector were much higher than those produced by using octano-hydroxamic acid collector. This meant that the overall recoveries of xenotime when using either depressant in the presence of sodium oleate collector were very low.

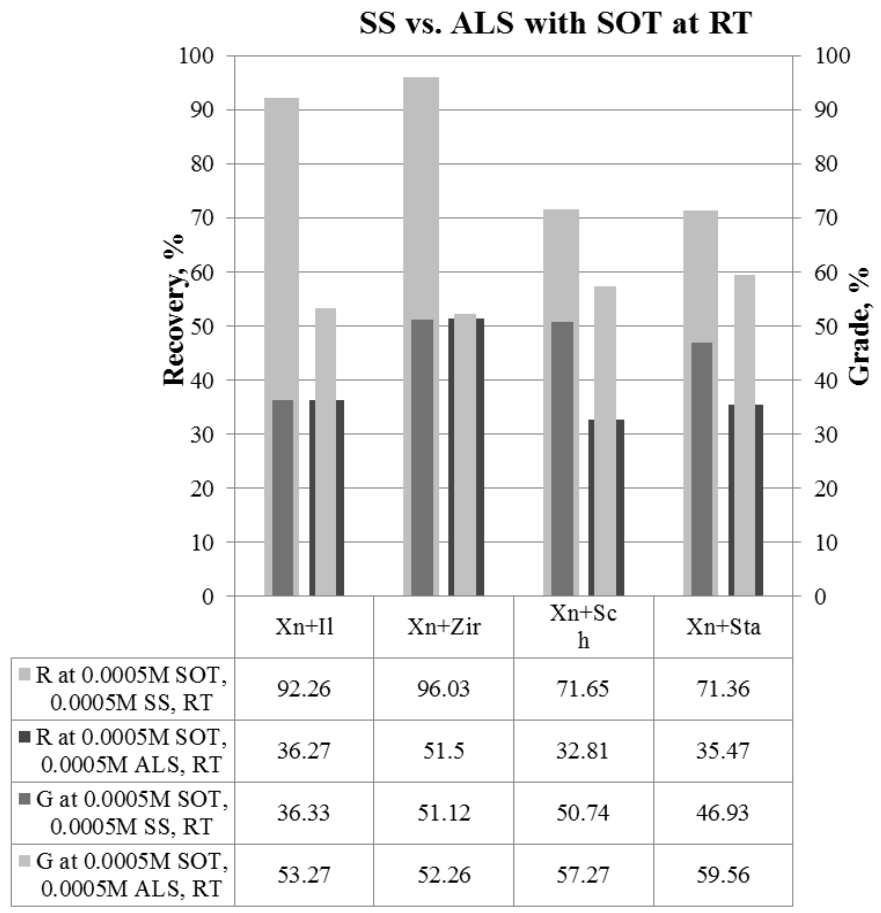

(b)

Figure 9: Comparisons between depressant effects of sodium silicate and ammonium lignosulfonate before the addtion of octano-hydroxamic or sodium oleate collector at $\mathrm{pH} 9$ and room temperature 
Accordingly, when using sodium oleate collector, the addition of depressants, especially in the use of ammonium lignosulfonate, appeared to decrease bubble stability. Many bubbles broke before they could be floated out of the cell. This, resulted in an abundance of xenotime particles in the flotation tailings. Clearly, these results display one shortcoming of using only single collector, sodium oleate. In this case, when in the presence of depressants, it helps to explain why other modifiers are necessary to enhance the stability of froths in the cell. Some flotation experiments studying this very issue have been done by previous researchers. In 2010, Wiese et al tested the effect of the combination of reagents (collectors, activators, depressants and frothers) on froth stability in batch flotation cells. He suggested that when replacing a short chain-length collector with a longer chain collector results in decreased froth stability[20]. This helps to explain the lowered recoveries when using sodium oleate collector than when using octano-hydroxamate collector. $\mathrm{He}$ also quite reasonably pointed out that the addition of frother increased froth stability. This may explain in part why the Mountain Pass industrial flotation plant uses both sodium oleate and tall oil in the flotation of bastnaesite[12]. Likewise, the Crago process also uses a combination of fuel oil and sodium oleate in phosphate flotation[21]. In 2012, Ravichandran and his coworkers also observed

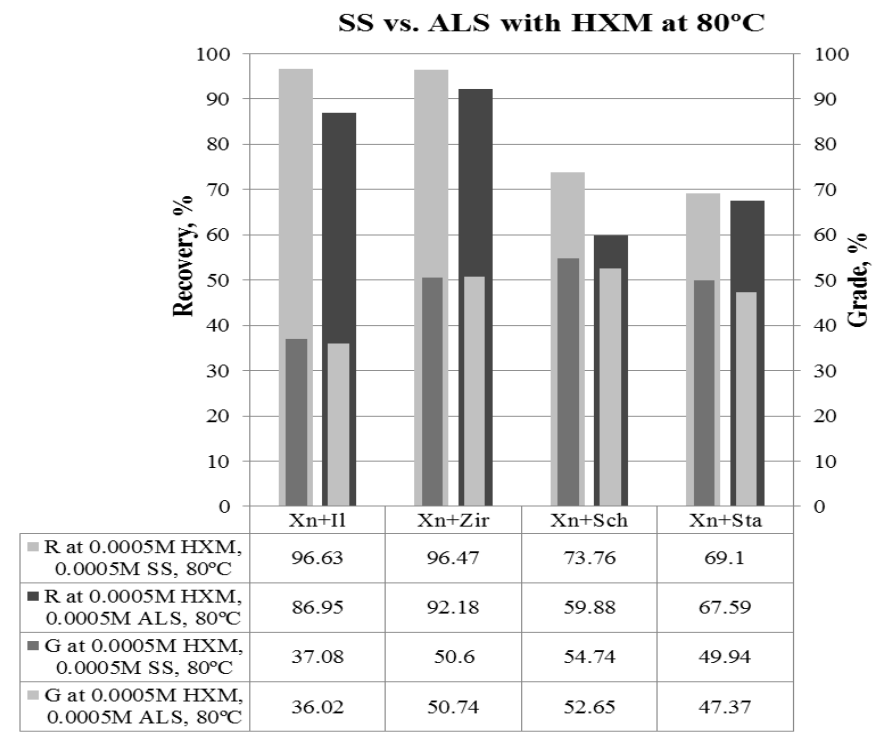

(a) similar phenomena in that the combination of a collector and frother would result better gas hold-up. Thus, better recoveries were found than when using collector alone[22].

In this research, ammonium lignosulfonate depressant worked less efficiently than sodium silicate depressant when using sodium oleate collector. Even though the changes in concentrate grade of xenotime found when using ammonium lignosulfonate was slightly higher than those found when using sodium silicate, the final recoveries were much lower. Presumably this is because ammonium lignosulfonate appeared to decrease the stability of the bubbles more than sodium silicate did in the presence of sodium oleate.

However, it is important to note, sodium silicate and ammonium lignosulfonate both helped the sodium oleate collector to separate xenotime from ilmenite. Again, this may be due to the $\mathrm{Fe}^{2+}$ ions on the surface of ilmenite. They may have favored a siliceous ion species or a lignosulfonate ion species more than the oleate ion species. This served to decrease the amount of active spots available on the ilmenite surface for any collector to adsorb on.

This resulted in the ilmenite surface remaining hydrophilic. Overall, in this research in the presence of sodium oleate collector, the ammonium lignosulfonate depressant had the best depressing power for the iron-bearing mineral ilmenite.

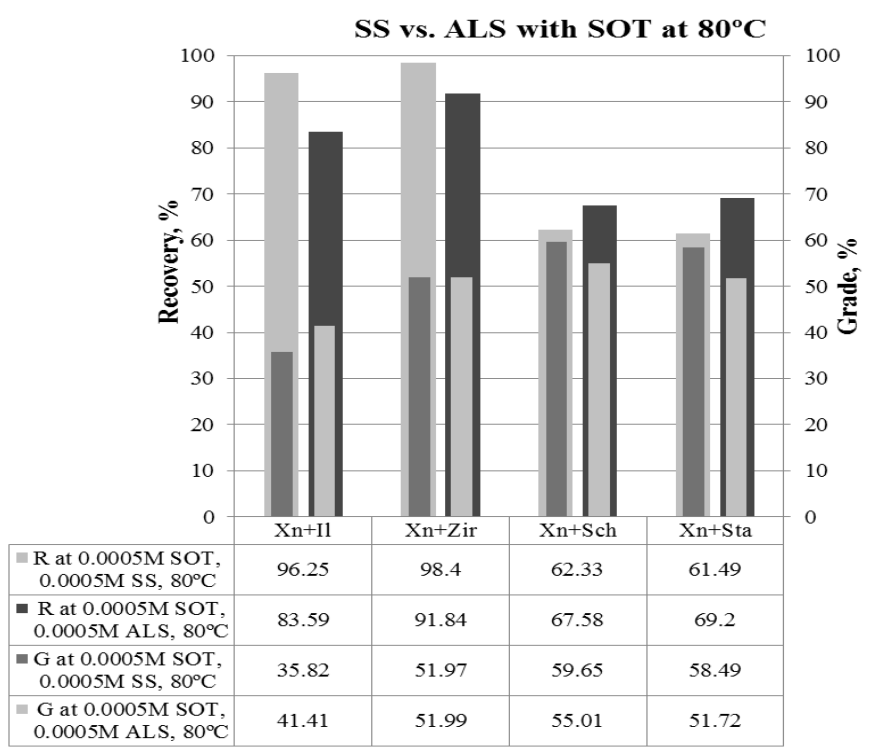

(b)

Figure 10: Comparisons between effects of sodium silicate and ammonium lignosulfonate depressants before the addtion of octano-hydroxamic or sodium oleate collectors at $\mathrm{pH} 9$ and $80^{\circ} \mathrm{C}$ 
The flotation of xenotime at $80^{\circ} \mathrm{C}$ was also conducted using the same collectors and depressants. As shown in Figure 10(a), at pH 9 and $80^{\circ} \mathrm{C}$ with octano-hydroxamic acid collector, the recoveries of xenotime from the mixed samples when using sodium silicate as the depressant were slightly higher than when using ammonium lignosulfonate depressant. The grades of xenotime flotation concentrate when using sodium silicate depressant were also slightly higher than those produced when with ammonium lignosulfonate depressant. Except for the mixed samples with of xenotime and zircon, the grades were nearly always the same. The relatively lower recoveries derived from mixed samples of xenotime and ilmenite show that neither sodium silicate nor ammonium lignosulfonate function very well as depressants with octano-hydroxamate collector at any temperature.

According to Figure 10(b), except for the mixed samples of xenotime and ilmenite, both sodium silicate and ammonium lignosulfonate enhanced the grades of xenotime concentrate significantly. The grade enhancement by sodium silicate was slightly better than those produced when using ammonium lignosulfonate. But the recoveries of mixed samples of xenotime and zircon were much higher than those regarding to samples containing schorl and staurolite gangue minerals.

For the mixed samples of xenotime and ilmenite, sodium silicate did not demonstrate any depressing power when using octano-hydroxamic acid collector or sodium oleate collector. As stated before, this is probably because the compounds formed with $\mathrm{Fe}^{2+}$ ions on the surface of ilmenite and the anionic collector ions were more stable than that those formed with silicate ions when at enhanced temperature.

As well, when this result is compared with the mixed samples of xenotime and zircon floated very well in the presence of any reagents when at $\mathrm{pH} 9$ and at room temperature. The weight recoveries were all over $90 \%$ and the grades of xenotime were above $15 \%$. As well, when this is result compared with the mixed samples containing schorl or staurolite gangue, relatively higher floatability of xenotime was shown.

\section{The Effect of Temperature}

The effect of temperature in froth flotation has been evaluated. In 1981, Pradip used higher temperatures in Denver flotation cell tests of bastnaesite ore obtained from Mountain Pass. He found that after the addition of soda ash and lignosulfonate as depressants, the concentrate recoveries and grades were both enhanced significantly at high temperatures in the presence of hydroxamate. In the case of the use of fatty acid collectors, the concentrate recoveries and grades were only slightly better[3]. In 1994, Cheng et al also studied the effect of temperature in the flotation of xenotime using oleic acid as the collector. He concluded that the performance of oleic acid was highly sensitive to temperature. The higher solubility of this weak acid at higher temperatures enhanced its adsorption density on the xenotime surface. Therefore, better flotation performance was found with the use of higher temperatures.[14]. It is thought that high temperatures can enhance the free energy in the solid-liquid system. So, more active spots on a particle surface would be available for more dissolved anionic collector ions to adsorb on.

In order to confirm this theory, adsorption density tests with xenotime were also conducted by using octano-hydroxamic acid as the collector. For the adsorption testing, the "ferric hydroxamate method" was used to measure the adsorption density [9].

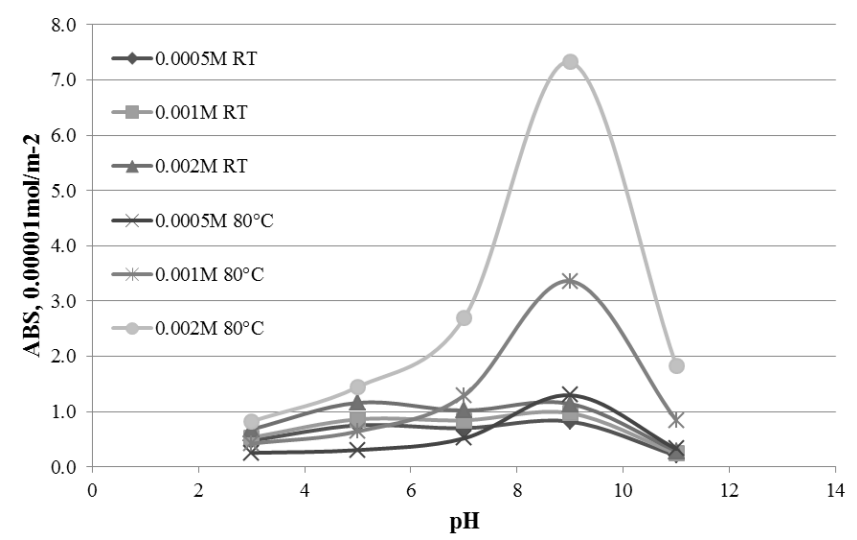

Figure 11: Adsorption densities of xenotime a function of $\mathrm{pH}$ with different concentration of octano-hydroxamic acid solution after shaking for 20 hours at room temperature and $80^{\circ} \mathrm{C}$

As shown in Figure 11, the adsorption densities of octano-hydroxamic ions on the surface of xenotime reached equilibrium with three different concentrations of this collector used at room temperature. But this effect was enhanced 
significantly at $80^{\circ} \mathrm{C}$ when more collector ions were available in the system. This was especially true when using a $\mathrm{pH}$ of 9 . These adsorption results appear in accordance with the effect of temperature theories mentioned previously.

In this research, flotation conducted when using sodium oleate collector and ammonium lignosulfonate depressant, the flotation results showed a similar effect. In Figure 12, the weight recoveries were much better at $80^{\circ} \mathrm{C}$ than at room temperature. The changes in concentrate grade were very close except for the mixed sample of xenotime and ilmenite. In this case, the concentrate grades were much lower at $80^{\circ} \mathrm{C}$ than when using room temperature. The results suggest that elevated temperature has a strong positive effect on the performance of sodium oleate and ammonium lignosulfonate. In contrast, as Figure 9(a) and Figure 10(a) show, the effect of temperature on the performance of octano-hydroxamic acid in the presence of depressants was of limited success. This could explain why the Bayan Obo industrial operation uses hydroxamate collectors at ambient temperature[6]. However, conversely, the Mountain Pass industrial operation uses sodium oleate collectors at elevated temperatures [12].

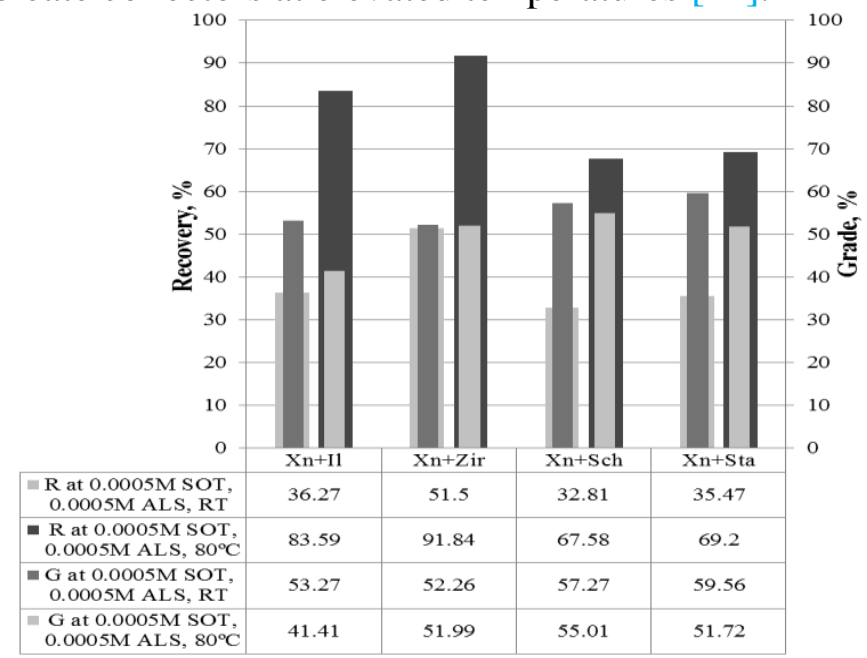

Figure 12: Effect of temperature on recoveries and grades in the presence of sodium oleate and ammonium lignosulfonate at room temperature and $80^{\circ} \mathrm{C}$, at $\mathrm{pH} 9$.

In addition, the bubble stability noted with use of a sodium oleate collector was lower at elevated temperature than at room temperature. It was witnessed that small bubbles merged into big ones when floating at elevated temperature and then broke at the surface of solution. In contrast, the bubble stability with octano-hydroxamic acid collector remained good even at higher temperatures. Also, with the use of octano-hydroxamic collector, the bubbles appeared to generate faster at high temperature.

\section{Conclusions}

In the microflotation tests of xenotime and the selected gangue minerals, ilmenite, zircon, schorl and staurolite, several conclusions can be made based on the results.

1. Both octano-hydroxamic acid and sodium oleate are effective collectors in the flotation of xenotime. The maximum weight recoveries of xenotime found when using octano-hydroxamic acid collector in the absence of depressants occurs in the $\mathrm{pH}$ range from 5 to 9 . Conversely, sodium oleate collectors have a narrower effective $\mathrm{pH}$ range of 7 to 9 . Hence, in this research, the optimum $\mathrm{pH}$ found to separate xenotime from the selected gangue minerals was deemed to be $\mathrm{pH} 9$.

2. At a $\mathrm{pH}$ of 9 and room temperature, the grades of concentrate produced when using sodium oleate collector are comparatively higher than those found when using octano-hydroxamic acid. All recoveries are close and all are above 93\%. However, in the absence of a depressant, sodium oleate collector seems to have better selectivity than octano-hydroxamic acid collector in xenotime flotation recovery from the selected gangue minerals.

3. The depressants, sodium silicate and ammonium lignosulfonate work well along with octano-hydroxamic acid collector to float xenotime from the selected silicate gangue minerals. This is seen at either room temperature or $80^{\circ} \mathrm{C}$. But neither depressant exhibits depressing power against ilmenite when using octano-hydoxamic acid. However, both depressants are efficient when used in the presence of sodium oleate collector. In this case, they both effectively depress all the gangue minerals including ilmenite at room temperature.

4. The bubbles formed in with the use of octanohydroxamic acid collector appear more stable than those formed when using sodium oleate. This appears to play an important role in the better weight xenotime recoveries obtained when using octano-hydroxamic acid as the collector.

5. The stability of bubbles is a significant factor in the performance of flotation. Extreme pHs, 
enhanced temperature and the addition of depressants can all partially affect the stability of bubbles and affect the weight recoveries of xenotime.

6. Ammonium lignosulfonate is a better depressant than sodium silicate in the depression of ilmenite when using sodium oleate collector. It results in a higher grade concentrate. However, in this case, the xenotime recoveries are worse when using ammonium lignosulfonate as the depressant. The reason behind this most probably due to active $\mathrm{Fe}^{2+}$ ions. These may favor ammonium lignosulfonate interactions more than those with sodium silicate and sodium oleate.

7. Temperature plays an important role in the flotation of xenotime from selected gangue minerals. While temperature appears to decrease the bubble stability when using sodium oleate collector alone, temperature also enhances the performance of ammonium lignosulfonate in the presence of sodium oleate. In this case, the recoveries of xenotime are increased significantly and the grades of the concentrate also remain high. However, temperature enhances the grades but decreases the recoveries when using octano-hydroxamic acid as the collector in the presence of depressants.

8. Based upon this research, to float xenotime from Fe-bearing gangue minerals, a combination of sodium oleate collector and ammonium lignosulfonate depressant at an elevated temperature would be the best. In order to float xenotime from silicate gangue minerals, a combination of sodium oleate collector in conjunction with sodium silicate depressant at room temperature would be best.

\section{Acknowledgement}

This research has been supported by the Critical Materials Institute, an Energy Innovation $\mathrm{Hub}$ funded by the U.S. Department of Energy, Office of Energy Efficiency and Renewable Energy, Advanced Manufacturing Office.

\section{References}

1. Sis H. and Chander S., "Improving froth characteristics and flotation recovery of phosphate ores with nonionic surfactants." Minerals engineering 16.7 (2003): 587-595.

2. Viswanathan K. V., Madhavan T. R., and Majumdar K. K., "Selective flotation of beach sand monazite." Mining Magazine 113.1 (1965): 17-23.
3. Pradip, "The Surface Properties and Flotation of Rare-Earth Minerals." Diss. University of California, Berkeley, 1981.

4. Dho H. and Iwasaki I., "Role of sodium silicate in phosphate flotation." Minerals \& Metallurgical Processing 7.4 (1990): 215-221.

5. Silva, J. P. P., Baltar C.A.M., Gonzaga R.S.G., Peres A.E.C. and Leite J.Y.P., "Identification of sodium silicate species used as flotation depressants." Minerals \& Metallurgical Processing Journal 29.4 (2012): 207-210.

6. Li L. and Yang X., "China's Rare Earth Ore Deposits and Beneficiation Techniques." 1st European Rare Earth Resources Conference, 2014.

7. Helmut K., Ulrich B. and Schulze H.J., "Freiberger Forschungshefte." A 437 (1968):7-22

8. Browning, W.C., "Lignosulfonate Challenge." Applied Polymer Symposia. Vol. 28. Wiley (1975): 109-123

9. Anderson C.D., "Improved understanding of rare earth surface chemistry and its application to froth flotation." Diss. Colorado School of Mines, 2015.

10. Weir D.R. and Roman M.G.S.B., "Recovery of gold from refractory auriferous iron-containing sulphidic concentrates." U.S. Patent No. 4,571,263. 18 Feb. 1986.

11. Sun W. and Yi L., "Reverse flotation iron increase and silicon removing method for refractory limonite." Chinese Patent, No. CN101234366A, 31 July, 2007.

12. Pradip and Fuerstenau D. W., "Design and development of novel flotation reagents for the beneficiation of Mountain Pass rare-earth ore." Minerals \& Metallurgical Processing Journal 30.1 (2013): 1-9.

13. Quast K. B., "A review of hematite flotation using 12-carbon chain collectors."Minerals Engineering 13.13 (2000): 1361-1376.

14. Cheng, T.W., Partridge A.C., Tran T. and Wong P.L.M., "The surface properties and flotation behaviour of xenotime." Minerals engineering 7.9 (1994): 1085-1098.

15. Cui, J., Hope, G. A., and Buckley, A. N. "Spectroscopic investigation of the interaction of hydroxamate with bastnaesite (cerium) and rare earth oxides." Minerals Engineering, 36, (2012): 91-99.

16. Cheng T.W., Holtham P. N. and Tran T., "Froth flotation of monazite and xenotime." Minerals engineering 6.4 (1993): 341-351.

17. Fan, X., Waters K.E., Rowson N.A. and Parker D.J., "Modification of ilmenite surface chemistry for enhancing surfactants adsorption and bubble attachment." Journal of colloid and interface science 329.1 (2009): 167-172.

18. Hosten C., "Micro-floatability of rutile and zircon with soap and amine type collectors." Physicochemical Problems of Mineral Processing 35 (2001): 161-170. 
19. Pavez O., Brandao P. R. G., and Peres A. E. C., "Adsorption of oleate and octyl-hydroxamate on to rare-earths minerals." Minerals Engineering 9.3 (1996): 357-366.

20. Wiese J., Harris P. and Bradshaw D., "The effect of the reagent suite on froth stability in laboratory scale batch flotation tests." Minerals Engineering 24.9 (2011): 995-1003.
21. Guan C., "Theoretical background of the Crago phosphate flotation process." Minerals \& Metallurgical Processing Journal 26.2 (2009): 55-64.

22. Ravichandran V., Eswaraiah C., Sakthivel R., Biswal S.K. and Manisankar P., "Gas dispersion characteristics of flotation reagents." Powder Technology 235 (2013): 329-335. 